\title{
The Olive Core, a Promoter Material for the Adsorption of Dyes: Effects on Certain Parameters, Kinetic and Thermodynamic Study
}

\author{
AHDE EL IMACHE* and KAMAR OUAZZANI \\ School of Technology, P.O. Box 2427, Sidi Mohammed Ben Abdellah University, Fez, Morocco. \\ ${ }^{*}$ Corresponding author E-mail: ahde.elimache@ usmba.ac.ma
}

http://dx.doi.org/10.13005/ojc/340624

(Received: April 20, 2018; Accepted: October 23, 2018)

\begin{abstract}
In this study, the Moroccan Olive Core was chosen for the preparation of a bio-adsorbent for the purpose of using it as a natural support to remove two synthetic dyes: Methyl Blue and Crystal Violet from aqueous solutions. The adsorbent characterization techniques were used: Fourier transform infrared spectroscopy and scanning electron microscopy. Influence of some parameters is studied to characterize the adsorption process: contact time (0-45 min.), temperature (25 -100 ${ }^{\circ} \mathrm{C}$ ) and initial concentration of MB and CV (10-30 mg.L-1). Langmuir, Freundlich and DubininRadushkevich isotherm models were used to describe the adsorption equilibrium. The equilibrium is perfectly described by the Freundlich model whose correlation coefficient is equal to 0.995 for $\mathrm{MB}$ and 0.991 for CV. Thermodynamic parameters were valued, and they showed that, for both dyes, the adsorption on MOC is endothermic and spontaneous.
\end{abstract}

Keywords: Olive core(OC), Methyl blue, Crystal violet(CV), Dye adsorption, Isotherm,

\section{INTRODUCTION}

Water pollution caused by dyes requires a special interest of the environmental society, especially researchers. Several anthropogenic activities use dyes in their manufacturing stages, like textile and paper industry, tannery, food processing, printing and cosmetics industry ${ }^{1}$. In the dying process, much of the dye applied is lost because the low levels of dye-fiber fixation ${ }^{2}$. Direct disposal of textile wastewater into the environment can cause serious environmental damage such as biological accumulation of dye molecules in fish. Consumption of this contaminated seafood can lead to undesirable and irreversible effects on the human nervous system $^{3}$. Given the potential dangers caused by dyes molecules on human health, recently, many approaches have been explored to develop cheaper and more efficient technologies, both to reduce the amount of wastewater produced and improve the quality of the treated effluent such as membrane filtration and adsorption ${ }^{4}$. Adsorption has become one of the most used alternative treatments used to reduce the level of dyes in water effluent. Recently, the search for low-cost adsorbents with high capacity of adsorption has intensified ${ }^{5}$. Several studies of

This is an Open Access article licensed under a Creative Commons license: Attribution 4.0 International (CC- BY). Published by Oriental Scientific Publishing Company @ 2018 
removing dyes and other pollutants using low-cost adsorbent were executed by many reviewers, e.g: agricultural and household waste ${ }^{6}$, industrial waste ${ }^{7}$, sludge ${ }^{8}$, sea materials ${ }^{9}$, soil and minerals ${ }^{10}$. Among these resources, agricultural waste remains the most interesting for several reasons, in particular for their availability and low cost. However, few studies concern the application of olive core as adsorbents ${ }^{11}$, specifically in Mediterranean countries as Morocco, where the national farms have a production of about $1,500,000$ tons of olives and the objectives of the Green Morocco Plan for 2020 in terms of olive production is to reach 2500000 tons $^{12}$. Nevertheless, studies on the removal of dyes using the solid residues of olive cores by adsorption are still scarce. However, this bio-adsorbent have not been studied for the removal of methylene blue and crystal violet. This study includes the adsorption behavior of those dyes onto OC, which is not reported previously. These cationic dyes are chosen for their multitude of application areas. Methylene blue is selected herein because of her widespread application in medicine, biological staining and chemistry (as redox indicator, water testing $)^{13}$. Crystal violet is used to dye paper, to colorize different products such as fertilizers and detergents, to human and veterinary pharmacopoeia for a long time ${ }^{14}$. The adsorption capacity of MB and $\mathrm{CV}$ on $\mathrm{OC}$ was investigated according to the $\mathrm{pH}$, contact time, initial dye concentration and temperature. Three isotherm models (Langmuir, Freundlich and Dubini- Radushkevich) were used to describe adsorption. To describe kinetic data, two models were adopted: the pseudo-first-order and pseudo-second-order kinetic models. Furthermore, thermodynamic parameters, such as $\Delta \mathrm{G}, \Delta \mathrm{H}$ and $\Delta S$, were examined.

\section{EXPERIMENTAL}

\section{Materials and methods}

Olive core was obtained from a canning industry that, mechanically, separates the stone from the skin. The $\mathrm{OC}$ is rinsed with distilled water and dried in air oven at $105{ }^{\circ} \mathrm{C}$ overnight. Then, it was ground to particle size of $0.4 \mathrm{~mm}$ and stored hermetically for further use. The dyes considered in this study are methylene blue and crystal violet, with very high degree of purity $(98 \%)$; they were provided by Biochem Chemopharma, Great Britain. The dyes concentration was measured by UV-Visible spectroscopy (Jasco V530) respectively for the MB and the $\mathrm{CV}$ at a wavelength of $\lambda \max =665 \mathrm{~nm}$ and $\lambda \max =590 \mathrm{~nm}$. The characterization of the olive core was carried out by BRUKER's Fourier Transform Infra-Red Spectroscopy (Vertex 70) by scanning a wavelength range of 400 to $7500 \mathrm{~cm}^{-1}$, and by the Electron Microscopy at Scanning (Quanta $200 \mathrm{FEI}$ ), with a magnification of $1000 \mathrm{x}, 2000 \mathrm{x}$ and 4000x. Table 1 summarized a structural and physico-chemical characteristics of dyes. A stock solution of each dye was prepared at a concentration of $100 \mathrm{mg}^{-\mathrm{I}^{-1}}$ in distilled water. Colored solutions of different concentrations, used in this study, were prepared using dilution of the stock solution with distilled water.

Table 1: Dyes characteristics

\begin{tabular}{lcccc}
\hline Dye & Chemical formula & Molecular weight $\left(\mathrm{g} \mathrm{mol}^{-1}\right)$ & $\lambda \max (\mathrm{nm})$ & Type \\
\hline Methylene Bleu & $\mathrm{C}_{16} \mathrm{H}_{18} \mathrm{ClN}_{3} \mathrm{~S}$ & 319.86 & 665 & Cationic dye \\
Crystal violet & $\mathrm{C}_{25} \mathrm{H}_{30} \mathrm{CIN}_{3}$ & 407,98 & 590 & Cationic dye \\
\hline
\end{tabular}

\section{Batch adsorption experiment}

In order to evaluate the biosorption property of OC, adsorption experiments of Methylene Blue and Crystal Violet were conducted by varying initial dyes concentration, $\mathrm{pH}$ and temperature of solution. The solution $\mathrm{pH}$ was modified by the addition of $\mathrm{NaOH}$ $(0.1 \mathrm{M})$ or $\mathrm{HCl}(0.1 \mathrm{M})$. Adsorption experiments were performed (at $250 \mathrm{rpm}$ ) by mixing a mass of 1 and 2 $\mathrm{g}$ of $\mathrm{OC}$, for MB and CV respectively, in $100 \mathrm{ml}$ of the aqueous dye solution at $20 \mathrm{mg} \cdot \mathrm{L}^{-1}$. Colored solution was divided from the adsorbent by centrifugation at $2600 \mathrm{rpm}$ for 5 minutes. Absorbance of the supernatant was measured after sampling using a $0.45 \mu \mathrm{m}$ diameter filter syringe (Minisart, sartorium stedim biotech) by means of a Jasco V530 UV-Visible spectrometer at the corresponding wavelength. A calibration curve is performed with a range of known concentrations of $\mathrm{MB}$ and $\mathrm{CV}$ to determine the final concentration of the dyes in solutions. The different parameters studied included:

a) The effect of the contact time: (5 to $80 \mathrm{~min}$ ); b) The effect of the mass of the adsorbent 
$(0.5$ to $8 \mathrm{~g})$;

(c) The effect of the initial concentration: (10 to $\left.30 \mathrm{mg} \cdot \mathrm{L}^{-1}\right)$; These three effects were studied at constant temperature $25^{\circ} \mathrm{C}$ and unadjusted $\mathrm{pH}$.

d) The effect of pH:(2.6 to 12) ataconstant temperature and concentration $\left(25^{\circ} \mathrm{C}, 20 \mathrm{mg} \cdot \mathrm{L}^{-1}\right)$;

e) The effect of temperature: $\left(25\right.$ to $\left.100^{\circ} \mathrm{C}\right)$.

The adsorbed amount was calculated using the formula:

$Q_{e}\left(m g \cdot g^{-1}\right)=\frac{\left(C_{0}-C\right) \cdot V}{m}$

With

$Q_{e}$ is amount of equilibrium adsorption $\left(\mathrm{mg}^{-g^{-1}}\right)$,

$\mathrm{C}_{0}$ and $\mathrm{C}$ are initial and final concentration of dye (mg.L-1) in the solution V $(\mathrm{ml}), \mathrm{m}$ is the mass of the adsorbent (g).

The results of adsorption have been described by Freundlich, Langmuir and DubininRadushkevich models. The rate constant of adsorption was quantitatively determined by the pseudo-first order and pseudo-second order models.

\section{RESULTS AND DISCUSSION}

\section{Characterization of the adsorbent}

The OC were analyzed by Scanning

Electron Microscopy (SEM) to visualize their surface morphology and deduce its characteristics. Fig. 1 shows the SEM of the OC before and after the adsorption of dye. The material had a smooth, porous surface structure, indicating a good possibility of trapping $\mathrm{MB}$ and $\mathrm{CV}$ dyes in the surface of the adsorbent. After adsorption, the adsorbent surface OC showed a rough and corroded structure due to the coverage of the pores and the surface by the two molecules of adsorbed dyes. The surface coverage was confirmed by the reduction of pores after adsorption of MB and CV.

Fourier transform infrared spectroscopy was applied to identify characteristics of OC Fig. 2. The recorded spectrum is strongly dominated by a broad band ranging from 3200 to $3800 \mathrm{~cm}^{-1}$ which indicates the presence of the bound $[\mathrm{O}-\mathrm{H}]$ characteristic of the alcohol groups, confirmed by the presence of a [C-O] band between 1000 and
$1300 \mathrm{~cm}^{-1}$. Characteristic bands of stretching vibration $\left[\mathrm{CH}, \mathrm{CH}_{2}\right.$, and $\left.\mathrm{CH}_{3}\right]$ are observed in the range of 2924 and $2854 \mathrm{~cm}^{-1}$. The stretching vibration of carboxylic groups $[\mathrm{C}=\mathrm{O}]$ can be proved by the peak at $1745 \mathrm{~cm}^{-1}$. The intense peak at 1047 $\mathrm{cm}^{-1}$ along with the weak peak at $1215 \mathrm{~cm}^{-1}$ and the shoulder at $1139 \mathrm{~cm}^{-1}$ are [C-O] stretching vibrations of ethers and alcohols.

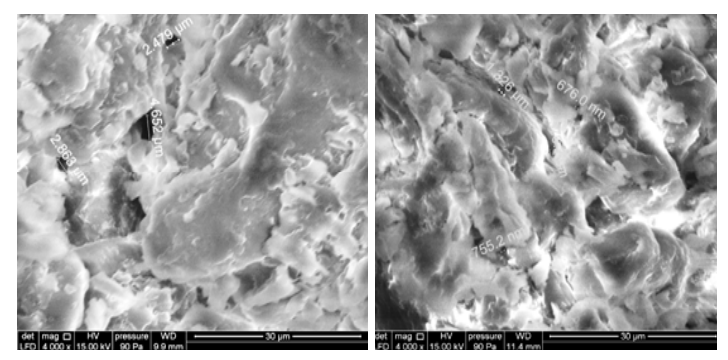

Fig. 1. SEM micrographs of OC (a) before and (b) after dye adsorption (4000x)

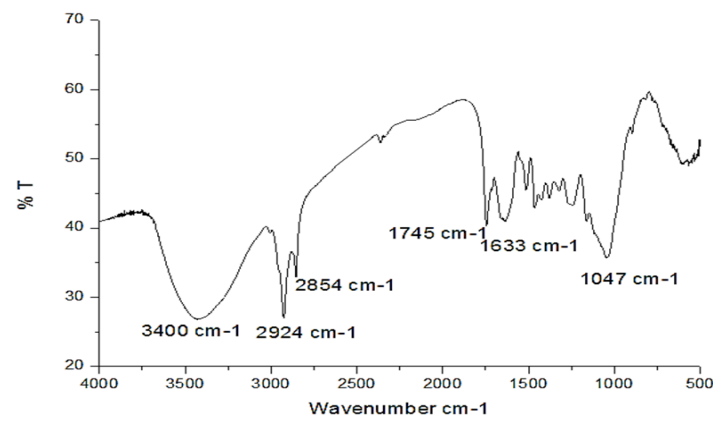

Fig. 2. FTIR spectra of OC

\section{Influence of initial pH}

One of the most significant parameters affecting the adsorbent's ability to treat water is the $\mathrm{pH}$ of the solution. Since the change in $\mathrm{pH}$ causes a change in the degree of ionization of the adsorbed molecule and changes the properties on the surface of the adsorbent, so the effectiveness of the adsorption depends on it. ${ }^{15-16}$ Fig. 3 described the influence of $\mathrm{pH}$ on the adsorption capacity of $\mathrm{MB}$ and $\mathrm{CV}$ on the Moroccan Olive Core at $25^{\circ} \mathrm{C}$. A slight increase in the adsorbed amount of $\mathrm{MB}$ and $\mathrm{CV}$ on MOC is observed when the $\mathrm{pH}$ of the solution increase from 2.6 to 6 . Thus, the adsorbed quantity remains relatively constant in the $\mathrm{pH}$ range from 6 to 12 for two dyes. This is probably due to the behavior of the cationic dyes in contact with the adsorbent at different $\mathrm{pH}$. By dissociating in water, dyes are positively charged, so they bind to the adsorbent in an acidic environment and repel in a basic environment. The adsorption can be considered by 
electrostatic interactions between the adsorbent and dyes. These interactions increase as the $\mathrm{pH}$ increases and the adsorbent surface becomes more negative as the solution becomes more and more basic ${ }^{17-18}$. Thus, the optimum $\mathrm{pH}$ is 5.5 and 5.8 respectively for $\mathrm{MB}$ and $\mathrm{CV}$ on $\mathrm{OC}$ adsorption.

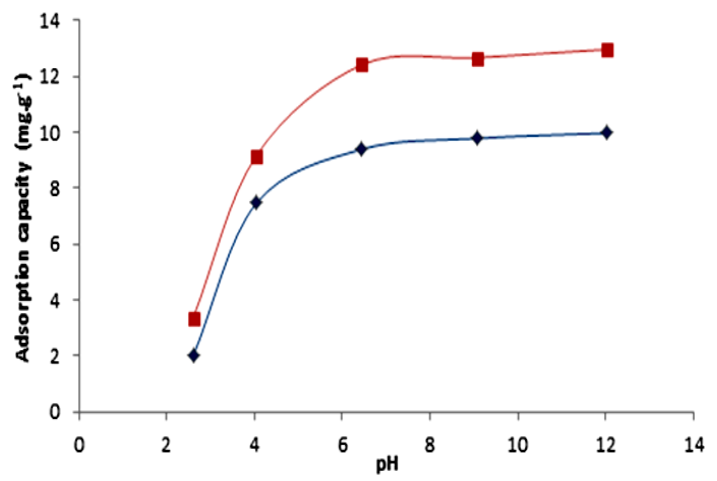

Fig. 3. Influence of pH on the adsorption capacity of MB $(\bullet)$ and $\mathrm{CV}(\square)$ on OC ( $\mathrm{C} 0=20 \mathrm{mg} \cdot \mathrm{L}^{-1}$, contact time: $\left.35 \mathrm{~min} . \mathrm{T}=25^{\circ} \mathrm{C}\right)$

Influence of contact time and adsorption kinetics

The impact of contact time on dyes adsorption for different concentrations was shown in Fig. 4. For both dyes, the adsorption rate was rapid at the first 10 minutes. It's probably due to the available active site of adsorption into OC surface. Subsequently, the adsorption rate stay fixed and eventually reached equilibrium due to the saturation of the OC surface sites ${ }^{19-20}$. For both dyes, a chosen contact time is 35 minutes. The adsorption mechanism of $\mathrm{MB}$ and $\mathrm{CV}$ dyes was evaluated by the most used kinetic models. Expressions of these models are given by equations 2 and 3 successively:

$$
\begin{aligned}
& \ln (Q e-Q t)=\ln Q e-k_{1} \cdot t \\
& \frac{t}{Q_{t}}=\frac{1}{k_{2} Q_{e}^{2}}+\frac{t}{Q_{e}}
\end{aligned}
$$

The kinetic parameters were determined from linear plots of $\operatorname{Ln}(\mathrm{Qe}-\mathrm{Qt})=\mathrm{f}(\mathrm{t})$ and $\mathrm{t} / \mathrm{Qt}=\mathrm{f}$ (t) for both models respectively. The results are summarized in Table 2.

As shown in Table 2, the calculated $Q_{t}$ values are very low compared to those measured $Q_{\text {exp }}$ for the two dyes. Based on the comparison of the correlation coefficients $R^{2}$, as it is noticed that the pseudo-first-order model are relatively low compared to the pseudo-second-order model, so unacceptable, leading to the conclusion that this model is far from describing the kinetics of adsorption of the two dyes. Alternatively, the pseudo-secondorder model displays $Q_{t}$ values that fit perfectly with $Q_{\text {exp }}$ measured values and with coefficients $R^{2}$ which are close to a unit. Thus, it can conclude that the adsorption system follows the pseudo-second order model, which suggests that the energy of adsorption sites influence on the adsorption rate. However, this model supposed that physiosorption may be the controlling mechanism for the rate at which $\mathrm{MB}$ and CV are adsorbed by OC, and will be confirmed and discussed later. These results are consistent with those described by numerous authors ${ }^{22}$.

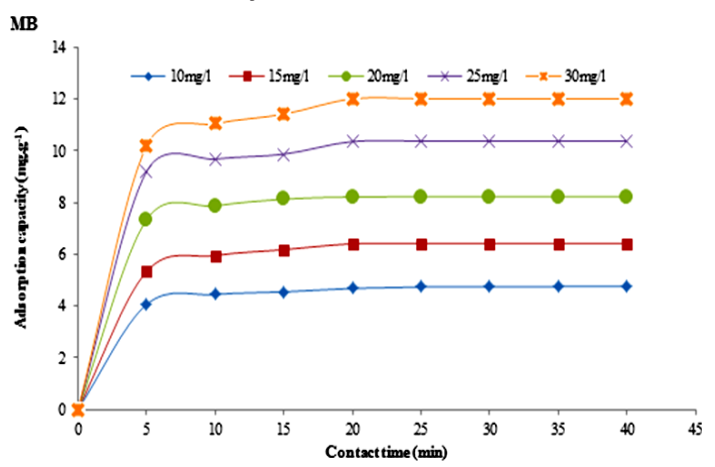

cv

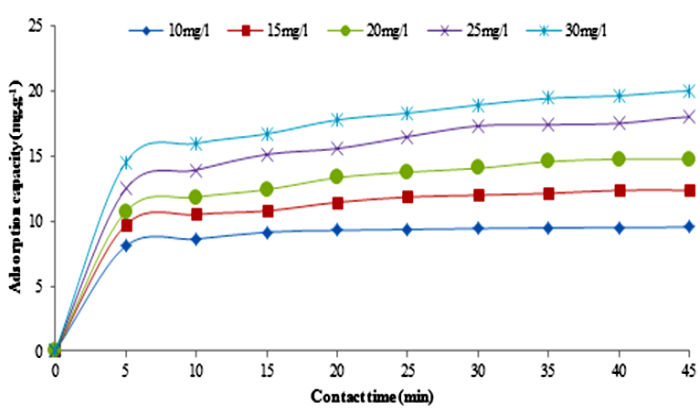

Fig. 4. Influence of contact time on the adsorption capacity of $\mathrm{MB}$ and $\mathrm{CV}$ on $\mathrm{OC}\left(\mathrm{pHBM}=5.5, \mathrm{pHCV}=5.8, \mathrm{~T}=25^{\circ} \mathrm{C}\right)$ Effect of Initial Dyes Concentration and Adsorption Isotherms

Figure 5 presents results concerning the study of the influence of the initial concentration of the two dyes (MB and CV) on the OC. As depicted, by increasing the concentration of the dye, the adsorption capacity increases at the same time, from 4.75 to $12.00 \mathrm{mg}^{-1} \mathrm{~g}^{-1}$ for $\mathrm{MB}$ and from 9.53 to 21.12 $\mathrm{mg} \cdot \mathrm{g}^{-1}$ for $\mathrm{CV}$, for dye concentrations ranging from 10 to $30 \mathrm{mg} \cdot \mathrm{L}^{-1}$. At a high initial dye concentration, the driving force exerted on the mass transfer is high, which explains the result found ${ }^{23-24}$. Indeed, a crossing of the percent dye removal curve and the adsorption capacity of the same dye can give an idea of the optimal concentration to be selected for subsequent testing. From the curves, it can be chosen the $30 \mathrm{mg} \cdot \mathrm{L}^{-1}$ for $\mathrm{MB}$ and the $20 \mathrm{mg} \cdot \mathrm{L}^{-1}$ for $\mathrm{CV}$. 


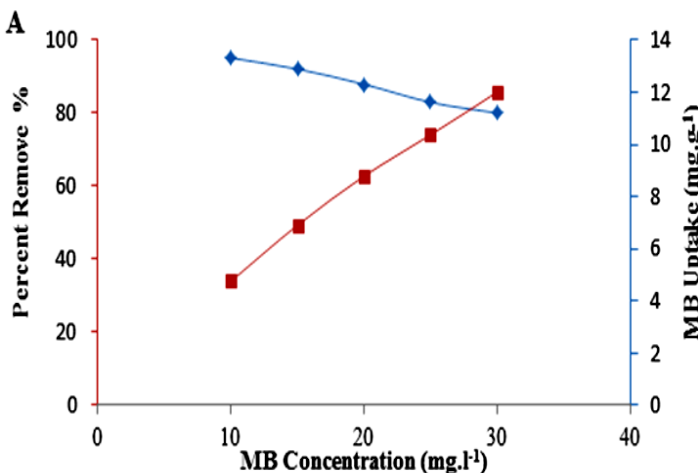

B

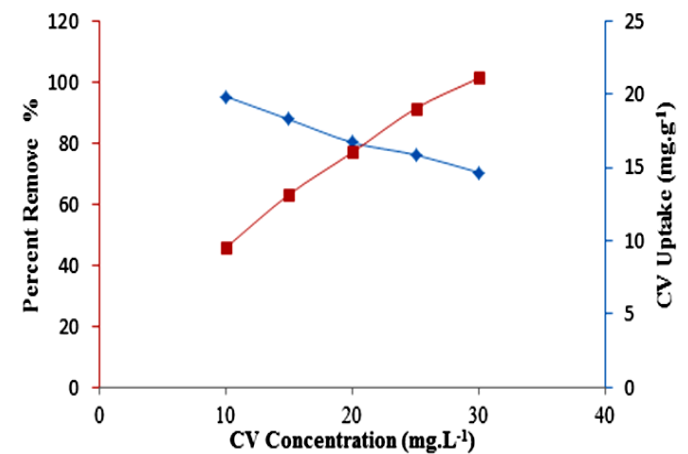

Fig. 5. Influence of initial concentration of MB (A) and CV

(B) on adsorption capacity onto OC the adsorbent, and to estimate the feasibility of the process: Freundlich, Langmuir and DubininRadushkevich (D-R) isotherms. The Freundlich isotherm expresses the characteristics of the heterogeneous surface and the intensity of the adsorption process with calculating the coefficient $\mathrm{n}$. It can be described by the following equation:

$$
\operatorname{Ln} Q_{e}=\operatorname{Ln} K_{F}+\frac{\operatorname{Ln} C_{e}}{n}
$$

With $\mathrm{K}_{\mathrm{F}}$ is the coefficient of Freundlich. The graphical representation of $L n\left(Q_{e}\right)$ as a function of $L n$ $\left(C_{e}\right)$ is a line whose slope is $1 / n$ and whose intercept is $\operatorname{Ln}\left(\mathrm{K}_{\mathrm{F}}\right)$. The $1 / \mathrm{n}$ value advises the validity of the adsorption. Favorable adsorption is making if the value of $1 / n$ is between 0 and 1 . The numerical values of $K_{F}$ and $1 / n$ are calculated respectively, from the intersection with the intercept and the slope of the isothermal line ${ }^{26}$. The Langmuir isotherm supposes that adsorption is monolayer and occurred at homogeneous sites for the adsorbent ${ }^{25}$. The following equation represents the Langmuir model with which $\mathrm{MB}$ and $\mathrm{CV}$ dye adsorption test data was processed on OC:

Table 2: Parameters of kinetic models

\begin{tabular}{|c|c|c|c|c|c|c|c|}
\hline \multicolumn{8}{|l|}{$\overline{\mathrm{MB}}$} \\
\hline \multirow[b]{2}{*}{$\begin{array}{l}\mathrm{C}_{0} \\
\left(\mathrm{mg} \cdot \mathrm{I}^{-1}\right)\end{array}$} & \multirow[b]{2}{*}{$\begin{array}{c}\text { Qexp } \\
\left(\mathrm{mg} \cdot \mathrm{g}^{-1}\right)\end{array}$} & \multicolumn{2}{|c|}{ First ordre } & \multicolumn{4}{|c|}{ Second ordre } \\
\hline & & $\begin{array}{c}\mathrm{K}_{1} \\
\left(\mathrm{~min}^{-1}\right)\end{array}$ & $\begin{array}{c}Q_{t} \\
\left(m g \cdot g^{-1}\right)\end{array}$ & \multicolumn{4}{|c|}{$\left(g \cdot \mathrm{mg}^{-1} \mathrm{~min}^{-1}\right)\left(m g \cdot g^{-1}\right)$} \\
\hline 10 & 4.755 & 0.379 & 1.8 & 0.983 & 0.201 & 4.902 & 0.999 \\
\hline 15 & 6.905 & 0.287 & 4.353 & 0.777 & 0.323 & 7.299 & 0.999 \\
\hline 20 & 8.79 & 0.274 & 4.051 & 0.722 & 0.187 & 9.091 & 0.999 \\
\hline 25 & 10.37 & 0.313 & 3.596 & 0.842 & 0.097 & 10.638 & 0.999 \\
\hline 30 & 12.005 & 0.347 & 5.473 & 0.887 & 0.097 & 12.5 & 0.999 \\
\hline \multicolumn{8}{|l|}{ CV } \\
\hline & \multicolumn{3}{|c|}{ First ordre } & \multicolumn{3}{|c|}{ Second ordre } & \\
\hline $\begin{array}{l}\mathrm{C}_{0} \\
\left(\mathrm{mg} \cdot \mathrm{I}^{-1}\right)\end{array}$ & $\begin{array}{c}\text { Qexp } \\
\left(\mathrm{mg} \cdot \mathrm{g}^{-1}\right)\end{array}$ & $\begin{array}{c}\mathrm{K}_{1} \\
\left(\mathrm{~min}^{-1}\right)\end{array}$ & $\begin{array}{c}Q_{t} \\
\left(m g \cdot g^{-1}\right)\end{array}$ & $\mathrm{R}^{2}$ & $\mathrm{mg}^{-1} \mathrm{mir}$ & $\begin{array}{c}Q_{t} \\
\left(m g \cdot g^{-1}\right)\end{array}$ & $\mathrm{R}^{2}$ \\
\hline$\overline{10}$ & 9.537 & 0.244 & 6.95659 & 0,984 & 0.093 & 9.804 & 0,999 \\
\hline 15 & 13.171 & 0.12 & 7.96965 & 0,870 & 0.021 & 13.699 & 0,997 \\
\hline 20 & 16.051 & 0.17 & 2.78813 & 0,747 & 0.01 & 17.544 & 0,997 \\
\hline 25 & 19.045 & 0.143 & 7.6413 & 0,829 & 0.009 & 20.408 & 0,997 \\
\hline 30 & 21.125 & 0.157 & 7.52666 & 0,828 & 0.009 & 22.727 & 0,997 \\
\hline
\end{tabular}

In order to describe interaction between the adsorbent and the adsorbate, several models of adsorption isotherms can be applied. Three models have been chosen to describe the interactions between the molecules of the dyes and those of

$Q_{e}=\frac{Q_{m} \cdot K_{L} \cdot C_{e}}{1+K_{L} \cdot C_{e}}$

Whither

$\mathrm{Q}_{\mathrm{m}}$ : the maximum adsorption capacity $\left(\mathrm{mg} \cdot \mathrm{g}^{-1}\right)$, 
$\mathrm{K}_{\mathrm{L}}$ : the equilibrium constant relative to the Langmuir model,

$\mathrm{C}_{\mathrm{e}}$ : the concentration of adsorbate at equilibrium $\left(\mathrm{mg} . \mathrm{I}^{-1}\right)$.

The $Q_{m}$ and $K_{L}$ values are determined from the intersection with the $y$-axis and the gradient of the line $C_{e} / Q_{e}=f\left(C_{e}\right)$.

In order to know the nature of adsorption, the Dubinin-Radushkevich (D-R) isotherm model, described as follow equations, is adopted ${ }^{27}$ :

$\left.Q_{e}=Q_{m} \cdot \exp -\beta \varepsilon^{2}\right)$

With

Qm: the theoretical isotherm saturation capacity $\left(\mathrm{mg} \cdot \mathrm{g}^{-1}\right)$, $\beta$ : the $D-R$ isotherm constant depending on temperature $\left(\mathrm{mol}^{2} \cdot \mathrm{kJ}^{-2}\right)$,

$\varepsilon$ : the $D-R$ isotherm constant depending on the equilibrium concentration of the dye $\left(\mathrm{mol}^{2} \cdot \mathrm{kJ}^{-2}\right)$.

This model is generally used to distinct between physical and chemical adsorption by calculating $E\left(\mathrm{~kJ}^{\mathrm{mol}}{ }^{-1}\right)$, the average energy of adsorption, given by the following formula:

$E=\frac{1}{(-2 \beta)^{1 / 2}}$

The linear plot of $\operatorname{Ln}\left(q_{e}\right)$ vs $\varepsilon^{2}$ is used to define model parameters. When $E$ is less than $8 \mathrm{~kJ} . \mathrm{mol}^{-1}$, it's the physic adsorption. For the chemical adsorption, $\mathrm{E}$ is between 8 and $16 \mathrm{~kJ} \mathrm{~mol}^{-1}$. Table 3 grouped the constants of the three used models.

Table 3: Freundlich, Langmuir and D-R parameters for the adsorption of $\mathrm{MB}$ and $\mathrm{CV}$ on $\mathrm{OC}$ at $25^{\circ} \mathrm{C}$

\begin{tabular}{lcccccccccc}
\hline \multicolumn{10}{c}{ Is } & \multicolumn{10}{c}{ Dotherm Models } \\
\hline Dye & $\mathrm{n}$ & $\mathrm{K}_{\mathrm{F}}$ & $\mathrm{R}^{2}$ & $\mathrm{q}_{\mathrm{m}}$ & $\mathrm{K}_{\mathrm{L}}$ & $\mathrm{R}^{2}$ & $\mathrm{q}_{\mathrm{m}}$ & $\mathrm{K}_{\mathrm{DR}}$ & $\mathrm{E}$ & $\mathrm{R}^{2}$ \\
\hline $\mathrm{MB}$ & 2,768 & 6,289 & 0,995 & 12,224 & 1,262 & 0,980 & 10,376 & 0,112 & 2,112 & 0,884 \\
$\mathrm{CV}$ & 3,706 & 11,481 & 0,991 & 19,193 & 2,051 & 0,910 & 17,801 & 0,082 & 2,469 & 0,780 \\
\hline
\end{tabular}

The adsorption capacity of OC calculated by Langmuir model is $12.22 \mathrm{mg} \cdot \mathrm{g}^{-1}$ for $\mathrm{MB}$ and $19.19 \mathrm{mg} . \mathrm{g}^{-1}$ for $\mathrm{CV}$ with a correlation coefficient of 0.980 and 0.910 for BM and CV, respectively. Table 4 summarized the calculate adsorption capacities in comparison with values from the bibliography. Mainly, the adsorption capacity of $\mathrm{OC}$ is considered average than the other adsorbents of the literature. The Freundlich model is also studied to evaluate the performance of $\mathrm{OC}$ in MB and CV removal. It's described the interactions of adsorbent molecules in heterogeneous system. For favorable dye adsorption, the Freundlich constant $1 / \mathrm{n}$ must be between 0 and 1. The numerical value of $1 / n$ is equal to 0.36 and 0.26 for the adsorption of $\mathrm{MB}$ and $\mathrm{CV}$ respectively; thus indicating a favorable adsorption according to the Freundlich model. The Freundlich equation is the model on the basis of adsorption onto a heterogeneous surface. According to the DR model, the average energy of adsorption $\mathrm{E}$ calculated is equivalent to $2.11 \mathrm{KJ} \mathrm{mol}^{-1}$ and $2.47 \mathrm{KJ} \mathrm{mol}^{-1}$ for the $\mathrm{MB}$ and the $\mathrm{CV}$ respectively, approving that the adsorption is physical nature.
Table 4: Comparison of OC with other adsorbents for MB and CV adsorption

\begin{tabular}{lccc}
\hline & Adsorption capacity $\left(\mathrm{mg}^{-1}\right)$ \\
Adsorbant & MB & CV & Reference \\
\hline Banana peel & 20.8 & - & 28 \\
Rice Husk & 40.6 & - & 29 \\
Coconut coir & 15.6 & - & 30 \\
Sawdust & - & 37.8 & 31 \\
Rice Husk & - & 44.9 & 32 \\
Pineapple leaf & - & 78.2 & 33 \\
\hline
\end{tabular}

\section{Effect of Temperature and Thermodynamic}

Temperature is another parameter that infects the physico-chemical parameters of the adsorption process ${ }^{34}$. The results relating to the study of the variation of the adsorption capacity of the two dyes on $\mathrm{OC}$ as a function of temperature are shown in Fig. 6. The results reveal that the temperature variation influences slightly the adsorption capacity of the two dyes on OC. This range increases from 7.43 to $9.07 \mathrm{mg} \cdot \mathrm{g}^{-1}$ for $\mathrm{MB}$ and from 15.74 to $19.20 \mathrm{mg} \cdot \mathrm{g}^{-1}$ for $\mathrm{CV}$ when the temperature changes from $25^{\circ} \mathrm{C}$ to $100^{\circ} \mathrm{C}$. From Fig. $6-\mathrm{A}$, It can be conclude that the adsorption is endothermic. Other authors have obtained similar results from the adsorption of MB 
on different materials including palm kernel fiber ${ }^{35}$ and the adsorption of $\mathrm{CV}$ on a cation exchange resin and mango stone ${ }^{36}$.

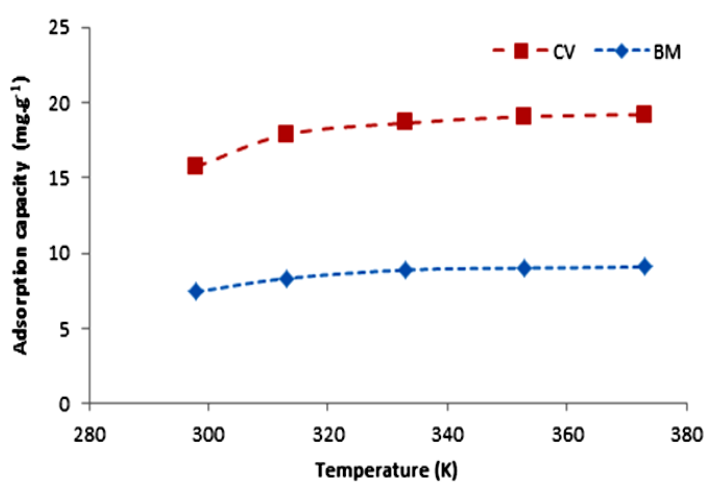

Fig. 6. Influence of temperature on adsorption capacity of dyes.

Thermodynamic parameters (enthalpy $\Delta \mathrm{H}^{\circ}$, entropy $\Delta S^{\circ}$, free enthalpy $\Delta \mathrm{G}^{\circ}$ ) were determined at $25,40,60.80$ and $100^{\circ} \mathrm{C}$, by the equation as follow:

$\Delta \mathrm{G}=-\mathrm{RT} \ln \mathrm{K}_{\mathrm{d}}$
With

$\mathrm{K}_{\mathrm{d}}$ : equilibrium constant,

$\mathrm{T}$ : temperature $(\mathrm{K})$,

R: gas constant (8.31447 J.moL $\left.{ }^{-1} \cdot \mathrm{K}^{-1}\right)$.

These parameters predict spontaneity, feasibility and exchange achieved at the adsorbentadsorbate system. The Van't Hoff equation allows us to estimate $\Delta \mathrm{H}$ and $\Delta \mathrm{S}$ values:

$$
\ln \mathrm{K}_{\mathrm{d}}=\frac{\Delta \mathrm{S}}{\mathrm{R}}-\frac{\Delta \mathrm{H}}{\mathrm{RT}}
$$

They are deduced from the plots of $\mathrm{Ln} \mathrm{K}_{\mathrm{d}}$ vs $(1 / T)$. Table 5 gathers the thermodynamic parameters of $\mathrm{MB}$ and $\mathrm{CV}$ adsorption on OC. For temperature range from 25 to $100^{\circ} \mathrm{C}$, The negative values of $\Delta \mathrm{G}^{\circ}$ shows that the process is spontaneous and feasible ${ }^{37}$. While the process is endothermic since the values of $\Delta \mathrm{H}^{\circ}$ are positive. Also, the positive values of $\Delta \mathrm{S}^{\circ}$ reveal a good affinity of $\mathrm{MB}$ and $\mathrm{CV}$ for $\mathrm{OC}$ and indicated the increasing in the degree of disorder at the solid/ solution interface during the process ${ }^{38}$.

Table 5: Parameters of thermodynamic study

\begin{tabular}{lccccccr}
\hline & \multicolumn{3}{c}{$\Delta \mathrm{G}^{\circ}\left(\mathrm{kj} \cdot \mathrm{mol}^{-1}\right)$} & & & $\Delta \mathrm{H}^{\circ}$ \\
$\left(\mathrm{kj} \cdot \mathrm{mol}^{-1}\right)$ & $\left(\mathrm{j} \cdot \mathrm{mol}^{-1} \cdot \mathrm{K}^{-1}\right)$ & $\mathrm{R}^{2}$ \\
\hline Adsorbat & 298 & 303 & 313 & 323 & & & \\
\hline CV & -3.763 & -5.093 & -5.979 & -6.865 & 22,647 & 88,627 & 0,944 \\
MB & -0.802 & -0.092 & -0.380 & -0.853 & 14,907 & 47,330 & 0,901 \\
\hline
\end{tabular}

\section{CONCLUSION}

This study has demonstrated the effectiveness of Moroccan Olive Core in removing $\mathrm{MB}$ and $\mathrm{CV}$ dyes in aqueous solution. Lots of parameters related to the operating conditions are examined (initial concentration of dyes, contact time, $\mathrm{pH}$ and temperature). According to the kinetic study, the equilibrium is established after $40 \mathrm{~min}$. respectively for $\mathrm{MB}$ and $\mathrm{CV}$ solutions at 10,20 and

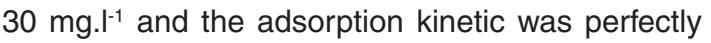
described by the pseudo-second-order model. The plot of the adsorption isotherms shows that the adsorption of $\mathrm{MB}$ and $\mathrm{CV}$ on the Moroccan Olive Core is well represented by the Langmuir model with a maximum adsorption capacity respectively

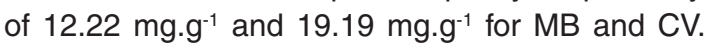
Freundlich model fit well as the Langmuir model with high correlation coefficient for both dyes. The thermodynamic parameters obtained suggest that the adsorption of the studied dyes on Moroccan Olive
Core is a spontaneous and endothermic process. Moroccan Olive Core has been found to be a carrier which has a generally moderate adsorption affinity to the methylene blue and crystal violet dyes. The abundance of this agriculture waste, generated by olive transformation, can provide a low-cost adsorption material that can potentially contribute to the treatment of concentrated effluents with dyes. One of the ways to develop is the chemical or physical activation of this bio-adsorbent to increase the bioavailability of adsorption sites and to improve the process.

\section{ACKNOWLEDGMENT}

The authors acknowledge sincerely the help delivered by the Department of Process Engineering of the Higher School of Technology of Sidi Mohammed Ben Abdellah University for the resources provided to carry out this research. 


\section{REFERENCES}

1. Yagub, M, T.; Sen, T. K.; Afroze, S.; Ang, H.M. Adv. Colloid. Interface Sci., 2014, 209. 172-84.

2. Ooi, J.; Lee,L.Y.; Zhang Hiew, B.Y.; Thangalazhy-Gopakumar, S.; Lim, S.S.; Gan, S. Bioresour. Technol., 2017, 245, 656-64.

3. Oz, M.; Lorke, D.E.; Hasan, M.; Petroianu, G.A. Med. Res. Rev., 2011, 31, 93-117.

4. Bentama, J.; Ouazzani, K.; Lakhliai, Z.; Ayadi. M. Desalination., 2004, 168, 295-9.

5. Anjaneyulu, Y.; Sreedhara Chary, N.; Samuel Suman Raj, D. Rev. Enviro. Sci. Biotechnol., 2005, 4, 245-73.

6. Pavan, F.A.; Lima, E.C.; Dias, S.L.P.; Mazzocato, A.C. J. Hazard. Mater., 2008, 150, 703-12.

7. Bhatnagar, A.; Vilar, V.J.P.; Botelho, C.M.S.; Boaventura, R.A.R. Environ. Technol., 2011. 32, 231-49.

8. Dhaouadi, H.; M'Henni, F. Chem. Eng. J., 2008, 138, 111-9.

9. Figueiredo, S.A.; Boaventura, R.A.; Loureiro, J.M. Purif. Technol., 2000, 20, 129-41.

10. El Imache, A.; Dousset, S.; Satrallah, A.; Dahchour, A. J. Enviro. Sci. Health. Part B., 2012, 47,161-7.

11. Shawabkeh, R.A.; Tutunji, M.F. Appl. Clay Sci., 2003, 24, 111-20.

12. Kaouah, F.; Boumaza, S.; Berrama, T.; Trari, M.; Bendjama, Z. J. Clean. Prod., 2013, 54. 296-306.

13. Département de l'agriculture, Ministère de l'agriculture, de la pêche maritime, du développement rurale, des eaux et des forêts ». http://www.agriculture.gov.ma.

14. Levin, R.L.; Degrange, M.A.; Bruno, G.F.; Del Mazo, C.D.; Taborda, D.J.; Griotti, J. J.; Boullon, F. J. Ann. Thorac. Surg., 2004, 77, 496-9.

15. Adams, E. Q.; Rosenstein, L. J. Am. Chem. Soc., 1914, 36, 1452-73.

16. Nandi, B. K.; Goswami, A.; Das, B.; Mondal, A. K.; Purkait, M. K. Sep Sci Technol., 2008. 43, 1382-403.

17. Duran, C.; Ozdes, D.; Gundogdu, A.; Senturk, H.B. J. Chem. Eng. Data., 2011, 56, 2136-47.

18. Nandi, B.; Goswami, A.; Purkait, M. Appl. Clay Sci., 2009, 42, 583-90.

19. Yao, Y.; He, B.; Xu, F.; Chen, X. Chem. Eng. J., 2011, 170, 82-98.
20. Adak, A.; Bandyopadhyay, M.; Pal, A. Sep. Purif. Technol., 2005, 44, 139-44.

21. Sadaf, S.; Bhatti, H.N. J. Taiwan Inst. Chem. Eng., 2014, 45, 541-53.

22. Belala, Z.; Jeguirim, M.; Belhachemi, M.; Addoun, F.; Trouvé, G. Desalination., 2011. 271, 80-7.

23. Ferreiraa, B.C.S.; Teodorob, F.S.; Magesteb, A.B.; Gil, L.F.; Pereira de Freitas, R.; Vinícius AlvesGurgelb, L. Ind. Crops Prod., 2015, 65, 521-34.

24. Bentahar, S.; Dbik, A.; El Khomri, M.; El Messaoudi, N.; Lacherai, A. J. Enviro. Chem. Eng., 2017, 5, 5921-32.

25. Senturk, H.B.; Ozdes, D.; Duran, C. Desalination., 2010, 252, 81-7.

27. Langmuir, I.; J. Chem. Soc., 1916, 38, 2221-95.

28. Freundlich, H.M.F. J. Phys. Chem., 1906. 57A. 385-470.

29. Fideles, R.A.; Ferreira, G.M.D.; Teodoro, F.S.; Adarme, O.F.H.; Mendes da Silva, L.H.; Gil, L.F.; Gurgel, L.V.A. J. Colloid Interface Sci., 2018, 515. 172-88.

30. Annadurai, G.; Juang, R.S.; Lee, D. J. J Hazard Mater., 2002, 92, 263-74.

31. Vadivelan, V.; Kumar, K.V. J Colloid Interface Sci., 2005, 286, 90-100.

32. Sharma, Y.C.; Upadhyay, S.N. Energy Fuels., 2009, 23, 2983-8.

33. Parab, H.; Sudersanan, M.; Shenoy, N.; Pathare, T.; Vaze. B. Clean - Soil, Air, Water., 2009, 37, 963-9.

34. Chakraborty, S.; Chowdhury, S.; Das Saha, P. Carbohydr. Polym., 2011, 86, 1533-41.

35. Chakraborty, S.; Chowdhury, S.; Saha, P.D. Appl. Water Sci., 2012, 1-7.

36. Fayoud, N.; Alami Younssi, S.; Tahiri, S.; Albizane, A. J. Mater. Environ. Sci., 2015, 11, 3295-306.

37. El sayed, G. O. Desalination., 2011, 272, 225-232.

38. Shoukat, S.; Bhatti, H.N.; Iqbal, M.; Noreen, S. Micropor. Mesopor. Mat., 2017, 239, 180-9.

39. Belaid, K.D.; Kacha, S. J. Water Sci., 2011, 242, 131-44.

40. Bayramoglu, G.; Altintas, B.; Yakup Arica, M. Chem. Eng. J., 2009, 152, 339-46. 